\title{
Aplicación del régimen de abuso de mercado (operaciones con información privilegiada y la manipulación del mercado): ¿hacia un modelo integrador de la aplicación de la ley penal y administrativa en la UE?*
}

Michiel J. J. P. Luchtman y John A. E. Vervaele**

\section{Resumen}

El texto estudia las normas relativas al abuso de mercado en la Unión Europea, la aplicación de la regulación de los mercados financieros y la manipulación del mercado. Así mismo, a partir del análisis de dos casos, muestra como en el marco de la regulación actual las autoridades nacionales en la UE no son en absoluto conscientes de la dimensión de sus tareas en Europa. Realiza un análisis de las propuestas legislativas recientes que tienen como objetivo crear igualdad de condiciones para los operadores económicos, los ciudadanos y las autoridades policiales. Plantea, además, una distinción entre las medidas propuestas en el ámbito del Derecho administrativo y el Derecho penal, para argumentar que estas propuestas aún no tienen en consideración los objetivos centrales de la UE.

\section{Palabras clave}

Abuso de mercado; aplicación de la ley; derechos fundamentales; ESMA; Eurojust; operaciones con información privilegiada; Seguridad y Justicia; Tratado de la Unión Europea; Tratado de Funcionamiento de la Unión Europea.

\footnotetext{
* Traducido del inglés al español a cargo de Luz Mª Palomero Rojo, Investigadora de la Universidad de Salamanca.

** Michiel Luchtman es profesor asociado en el Instituto Willem Pompe de Derecho Penal y Criminología e investigador en el Utrecht Centre for Regulation and Enforcement in Europeel (RENFORCE). John Vervaele es profesor en Derecho Penal Económico y Europeo y Co-Director del Utrecht Centre for Regulation and Enforcement in Europe (RENFORCE) en la Facultad de Derecho de Utrecht en los Países Bajos y profesor de Derecho Penal Europeo en el Colegio de Europa de Brujas, en Bélgica; es también Presidente de la Asociación Internacional de Derecho Penal (AIDP).
} 


\section{Introducción}

Desde hace mucho tiempo, la Unión Europea (en adelante UE) ha sido un importante motor para la integración de los mercados financieros en el continente europeo. Es posible decir que la internacionalización permanente ha impulsado el proceso de integración europea y la UE, a su vez, ha impulsado aún más este desarrollo mediante la eliminación de barreras interestatales a través de cuatro libertades y la armonización de las medidas. La UE se fijó objetivos ambiciosos para sí misma en el Tratado de Lisboa. El artículo 3 (2) del Tratado de la Unión Europea (en adelante TUE) ofrece a los ciudadanos europeos un espacio de libertad, seguridad y justicia (en adelante ELSJ) sin fronteras interiores, en el que esté garantizada la libre circulación de personas, simultáneamente con medidas adecuadas en materia de prevención y lucha contra la delincuencia. En lo que respecta al mercado interior, el artículo 26 (2), del Tratado de Funcionamiento de la Unión Europea (en adelante TFUE), además sostiene que el mercado interior implicará un espacio sin fronteras interiores en el que esté garantizada la libre circulación de mercancías, personas, servicios y capitales, de conformidad con las disposiciones de los tratados.

Este artículo parte de la hipótesis central de que estas ambiciones tienen consecuencias para la organización de la aplicación de la Ley. A pesar de que la facultad de hacer cumplir las leyes se considera que pertenece al núcleo del Estado-nación (y a la UE, por lo que se suele cumplir por las autoridades nacionales), dichas autoridades y sus facultades son una parte esencial del ordenamiento jurídico europeo. Estas no sólo tienen un conjunto de potestades con el fin de aplicar efectivamente las leyes de la UE en sus propios territorios, sino que también deben cooperar entre sí en casos transnacionales o en los casos nacionales en las que se necesita asistencia legal mutua (MLA, en siglas en inglés). Por consiguiente, la integración de los mercados financieros implica por sí misma, una responsabilidad conjunta de aquellas autoridades nacionales competentes involucradas, que no sólo se refiere a cuestiones de si la eficacia de la cooperación se ha de lograr entre dichas autoridades sino, también, en términos de quién es el responsable de la supervisión general y la protección de los derechos fundamentales. En un sistema de competencias estos términos se solapan y existe el riesgo real de que si todos son competentes, en última instancia nadie va a ser realmente 
responsable (Bovens, Curtin y Hart, 2010, pp. 44-46, 192-193; Busuioc, 2010, p. 8; Groenleer, 2009, pp. 103-104).

Nuestro análisis se centra en un área específica que siempre ha estado a la vanguardia de la evolución, es decir, las normas relativas a la aplicación de los casos de abuso de mercado. Cuando se trata de la aplicación de la regulación de los mercados financieros de la UE $\mathrm{y}$, particularmente, en la manipulación del mercado, las principales preguntas son: $i$ ) hay alguna necesidad de ejecución por parte de la UE; 2) si es así, está limitada a la jurisdicción prescriptiva o también incluye jurisdicción investigadora en el ELSJ (en la coordinación del desempeño supranacional); y 3) si incluye un proyecto integrado de la aplicación administrativa y penal? Empezamos el siguiente apartado con dos casos en los cuales se muestra que, en el marco de la regulación actual, las autoridades nacionales competentes no son en absoluto conscientes de la dimensión de sus tareas en Europa, que no sólo lleva a una duplicación del trabajo de las mismas sino a una mayor complicación en las situaciones jurídicas de las personas físicas y jurídicas afectadas. Seguidamente, proporcionamos una visión general de la agenda política de los órganos legislativos europeos y hacemos un análisis de las propuestas legislativas recientes que tienen como objetivo crear una igualdad de condiciones, no sólo para los operadores económicos y los ciudadanos, sino también para las autoridades policiales. Hacemos una distinción entre las medidas propuestas en el ámbito del Derecho administrativo y el Derecho penal. Luego, se argumenta que estas propuestas aún no tienen plenamente en consideración los objetivos centrales de la UE, tal como se formulan en los artículos 3 de TUE y 26 TFUE anteriormente mencionados. Terminamos con un breve resumen de nuestras conclusiones. Por último, debemos señalar que como este trabajo se centra en la aplicación del Derecho público (administrativo y penal, según ya se dijo), pasamos por alto la utilización de la ley en el ámbito del derecho privado y sus agentes.

\section{Acuerdos y análisis de problemas}

\section{El Fortis Bank: la manipulación del mercado y el abuso de mercado.}

En 2007, justo antes de la crisis financiera y la fusión de 2008, el Banco Santander, el Fortis Bank y el Royal Bank of Scotland obtuvieron el control sobre el Banco ABN Amro a través de una discrepante puja pública de adquisición, por la cantidad de 72 mil millones de euros, 
una de las más grandes en la historia de la industria de servicios financieros. La operación fue aprobada por la Comisión Europea (en adelante $\mathrm{CE}$ ), pero el Fortis Bank tuvo que vender algunos activos. Fortis Bank, el banco más grande de Benelux, tenía problemas para financiar su parte adquirida y decidió lanzarse al mercado de capitales para obtener nuevos ingresos y así poder ofrecer acciones nuevas. Dicha operación tuvo una amplia difusión. Aunque la ampliación de capital tuvo éxito, no fue suficiente para garantizar la posición financiera del Banco Fortis, pues el empeoramiento de la situación de los mercados financieros y la creciente desconfianza en el sector bancario lo llevaron al punto del colapso, hasta que los gobiernos de Bélgica, Holanda y Luxemburgo intervinieron y lo nacionalizaron, pues lo desmantelaron y vendieron parcialmente. Sin duda, esta apropiación y descomposición no fue hecha desde una perspectiva europea sino que, más bien, es un ejemplo típico de una actividad económica impulsada por el interés nacional.

Debido a la crisis de la empresa, rápidamente se plantearon dudas acerca de su integridad financiera y de la información proporcionada a los nuevos accionistas y a los ya existentes. Las normas relativas a la manipulación del mercado y al abuso de mercado se rigen, en parte, por la legislación Europea de mercados financieros (Directiva 6/2003/CE, 2003 enero 28, sobre operaciones con información privilegiada y la manipulación del mercado (abuso del mercado), (OJ EU L 96/16), y rigen en todos los estados miembros de la UE. Sin embargo, la aplicación de ellas en el caso Fortis ha sido fuertemente impulsada por agendas e intereses nacionales. Las infracciones llevadas a cabo con el abuso de mercado son las irregularidades administrativas y las infracciones penales, cometidas en Bélgica, Luxemburgo y en los Países Bajos; en estos tres países las personas jurídicas pueden ser declaradas responsables administrativamente y penalmente por este tipo de delitos.

No obstante, en Luxemburgo no se llevó a cabo ninguna acción por parte de las autoridades nacionales competentes, ni en el ámbito administrativo ni el judicial. Pero en los Países Bajos, las autoridades policiales y administrativas abrieron investigaciones contra el ex Banco Fortis por sospechas de manipulación del mercado y abuso de mercado. Asimismo, en Bélgica, tanto las autoridades administrativas como las judiciales que eran competentes, abrieron investigaciones contra el ex Banco Fortis y contra el director ejecutivo (en adelante CEO- Chief Executive Officer). Así las cosas, mientras existieron investigaciones y procedimientos concurrentes 
y paralelos en Bélgica y en los Países Bajos, en Luxemburgo no se realizó ninguna investigación.

En febrero de 2012, la Autoridad Holandesa de Mercados Financieros (AFM), fue la primera en concluir los procedimientos de investigación e impuso cuatro multas de $144.000 €$ a cada una de las dos personas jurídicas que constituyeron la Corporación del Fortis Bank, Fortis NV Bruselas y Fortis NV Utrecht (Véase, De Brauw Blackstone Westbroek, 2010; Fortis N.V. - gevestigd te Utrecht, 2010). Además, el Fortis Bank fue declarado culpable por manipulación del mercado y abuso de mercado en dos situaciones:

De un lado, después de la adquisición de ABN Amro, el consejero delegado del Fortis Bank organizó una conferencia de prensa en la que insistió en la fuerte y sana posición financiera del Fortis. Al hacer estas declaraciones, estaba engañando a los inversores; $y$, de otro lado, la CE obligó al Fortis Bank a vender algunas de las participaciones del grupo. Al introducir estas partes activas en el mercado, el Fortis Bank no publicó ninguna información negativa sobre la situación financiera del grupo y, con esa acción, manipuló la negociación de sus acciones en la bolsa de valores.

Ambas infracciones fueron hechas por los principales dirigentes, dando instrucciones a los dos grupos del Fortis; por ello, el importe total de la multa se redujo a un 50 por ciento para cada parte propietaria del grupo. La imposición de las multas administrativas por la AFM a las dos personas jurídicas que componen la organización del Fortis Bank, con seguridad, se han coordinado con las autoridades judiciales holandesas competentes. En los Países Bajos, el marco legal impone la obligación a las autoridades administrativas y judiciales de elegir en una etapa del proceso que vía de aplicación van a emplear, es decir, deben optar por imponer sanciones administrativas o penales (el llamado principio 'una vía'). No obstante, esto no impide la apertura de un proceso penal contra los ex CEOs; al respecto, la Fiscalía holandesa no ha hecho ninguna notificación formal sobre la existencia o no de alguna investigación judicial en curso $^{1}$. Se desconoce y es difícil de suponer si la dimensión europea del asunto en este caso, fue un factor relevante a la hora de tomar la decisión de ir por el camino de la ejecución administrativa, en vez de optar por la vía del Derecho penal. Pese a lo anterior, lo que está claro es la existencia de una acción unilateral por parte de las autoridades holandesas, sin ninguna coordinación con las administrativas y judiciales belgas. 
En junio de 2012, la Delegación de Ejecución Administrativa de Bélgica, específicamente la Autoridad de Servicios y Mercados Financieros (en adelante FSMA), encontró evidencias de que la empresa distribuyóinformación engañosa y el auditor administrativo pidió la imposición de multas de $500.000 €$ contra el ex Banco Fortis y multas de 250.000 a $500.000 €$ para tres de los directores ejecutivos. En junio de 2013, la comisión sancionadora de FSMA requirió al auditor para que revisara y evaluara a la entidad, para maximizar las multas contra el CEO al monto de $400.000 €$. Finalmente, en 2013, las autoridades judiciales belgas decidieron enjuiciar a siete ex CEOs por información engañosa, abuso de mercado, falsificación de documentos y engaños, pero optaron por no procesar al ex Banco Fortis o BNP Paribas Fortis (el nuevo dueño del banco).

Junto a estos procedimientos administrativos y penales, las víctimas interpusieron demandas civiles contra Fortis y contra su consejero delegado en diversas jurisdicciones $y$, cuando fue posible (como en Bélgica), también desempeñaron un papel activo en el arranque del proceso como parte civil en el proceso penal.

\section{Libor/Euribor: escándalo de la manipulación de los tipos de interés.}

La tasa interbancaria de Londres (en adelante Libor) es la que se emplea como promedio por los principales bancos en Londres y se cobra cuando ellos realizan préstamos a otros bancos; se calcula para diez divisas, incluyendo el dólar y el euro. Cerca de 20 bancos líderes en el mundo participan en los paneles de Libor (Véase. BBA, s.f.). Euribor es la abreviatura de Euro Interbank Offered Rate (tipo europeo de oferta interbancaria). Los tipos de Euribor se basan en los modelos de interés fijados por los paneles de alrededor de $40 \mathrm{o}$ 50 bancos europeos (Véase. Euribor panelbanks, s.f.). Ambas tasas de Libor y Euribor son las de referencia diaria para las hipotecas, productos de préstamos al consumidor, acuerdos de tipos futuros, opciones, swaps y otros instrumentos financieros; y, de este modo, todos ellos tienen efectos significativos en los consumidores y en los mercados financieros en todo el mundo.

Así las cosas, en 2012 salió a la luz que desde 1991 los paneles Libor y Euribor habían estado manipulando intencionadamente los tipos de interferencias, con el fin de aumentar las ganancias de los bancos. Varios bancos europeos se enfrentaron a las investigaciones y a los procesos acumulados, tanto en los EE.UU. 
como en los países europeos. Los bancos no tenían solo que hacer frente a las reclamaciones por daños civiles (en su mayoría en los EE.UU.) sino, también, a procedimientos punitivos por parte de las autoridades administrativas (los reguladores financieros y las autoridades competentes: la autoridad competente Europea y la autoridad competente de Suiza, abrieron un procedimiento por el comportamiento de cartel) y por parte de las autoridades judiciales.

Una de las entidades que estaba activa tanto en las tasas Libor como en las Euribor era el Barclays Bank PLC, una corporación de servicios financieros con sede en Londres y que tiene filiales bancarias en todo el mundo, incluso en los EE.UU. En el período 2007-2009, algunos operadores de swaps en Barclays solicitaron que determinados intermediarios en el Libor y Euribor de Barclays los sometieran a contribuciones que beneficiaran, mediante la negociación, las posiciones de los operadores económicos en lugar de aquéllas que cumplían con las definiciones de Libor y Euribor. Estos operadores de swaps propusieron, bien una contribución especial de Libor o Euribor para un exclusivo plazo y moneda, o hicieron propuestas en las que los intermediarios contribuyesen a una tasa más alta, más baja o sin cambios en un concreto plazo y en una moneda determinada. Los operadores de swaps hicieron estas solicitudes a través de mensajes electrónicos, conversaciones telefónicas y personales. Los demandantes de Libor y Euribor acordaron dar cabida, y atendieron las solicitudes de los operadores de swaps para favorecer las demandas del Libor y Euribor en nume-rosas ocasiones.

En junio 2012 el Barclays Bank PLC concluyó un acuerdo de noprosecución de la actuación en su contra con la División de Fraude del Departamento de Justicia de Estados Unidos, la Sección de Fraude (Fraud Section), al admitir su culpabilidad por la mala conducta relacionada con las propuestas de las tasas de Libor y Euribor y acordó pagar 160 millones de euros de penalización; con ello evitó ser procesado penalmente (Véase. U.S. Department of Justice, Criminal División, 2012). Como parte del acuerdo con el Departamento de Justicia ${ }^{2}$, Barclays reconoció y aceptó su responsabilidad por su conducta ilícita en una declaración sobre los hechos que se incorporó en el acuerdo. Según el pacto, Barclays proporcionó a los paneles Libor y Euribor propuestas que, en varias ocasiones, eran falsas, porque indebidamente tomaron en consideración las posiciones de negociación de sus operadores o inquietudes sobre su reputación, 
debido a la imagen negativa de los medios de comunicación en relación con sus alegaciones en Libor.

Ahora bien, como consecuencia de la admisión por parte de Barclays de su mala conducta, su cooperación extraordinaria, sus esfuerzos de remediación y ciertos factores y atenuantes, el Departamento decidió no procesarlo por proporcionar falsas contribuciones sobre Libor y Euribor, a condición de que cumpliese con sus obligaciones en curso, dentro del marco del acuerdo y en un período de dos años. El acuerdo de no enjuiciar, adviértase, solo se aplicó al Barclays y no cobijó a sus empleados o directivos o a cualquier otro individuo perteneciente a esa empresa. La investigación criminal del Departamento de Justicia sobre la manipulación de las tasas del Libor y Euribor continúa con actuaciones en curso contra otras instituciones financieras e individuos. El acuerdo requiere que Barclays siga cooperando con el Departamento en sus investigaciones en curso. Además, se entiende que este Acuerdo no obliga a ninguna autoridad fiscal federal, estatal, local o extranjera que no sea la Sección de Fraude. Sin embargo, la Sección de Fraude requerirá de la cooperación de Barclays a la atención de otros miembros de las fiscalías y de investigaciones, cuando se lo soliciten.

Por otra parte, también en Junio de 2012, el Banco Barclays fue multado con 200 millones de dólares por la Comisión de Comercio de los Mercados de Futuros de EE.UU. y con 59.5 millones de libras por la Autoridad de Servicios Financieros del Reino Unido por intento de manipulación de las tasas de Libor y Euribor (Véase. FSA, 2012, Barclays fined £59.5 million for significant failings in relation to LIBOR and EURIBOR; FSA, 2012, Final notice). En junio del 2012, la Oficina de Fraudes Graves del Reino Unido anunció que iniciaría investigaciones penales por el escándalo de las tasas de Libor, contra diversas personas incluido el consejero delegado de Barclays (Treanor, 2012).

Como Barclays, diversos bancos se enfrentaron a acciones acumulativas similares de ejecución. En diciembre de 2012, el UBS suizo acordó pagar 1.5 billones de dólares (1.2 billones de dólares al Departamento de Justicia de EE.UU. y a la Comisión de Comercio de los Mercados Futuros, 160 millones de libras a la Autoridad de Servicios Financieros del Reino Unido y 60 millones de francos suizos a la Autoridad de Supervisión del Mercado Financiero Suizo por su papel en el escándalo de las tasas). A mediados de 2012, el Banco Nacional de Holanda (DNB) y las Autoridades de Mercados 
Financieros holandesas, comenzaron las investigaciones administrativas por el escándalo de las tasas del Libor y Euribor (DNB en AFM onderzoeken manipulatie Libor-rente, 2012), pero recurrieron a su deber de confidencialidad para negarse a dar más información sobre las investigaciones concretas. Las autoridades judiciales holandesas no estaban dispuestas a confirmar ninguna investigación judicial oficial sobre el holandés Rabobank; mientras tanto, este acordó con algunos organismos reguladores, como el Departamento de Justicia de EE.UU., la Comisión de Comercio de los Mercados Futuros de Estados Unidos y la Autoridad de Conducta Financiera del Reino Unido, el pago de una multa de 774 millones de euros.

En diciembre de 2013, la Autoridad de la Competencia de la UE hizo un acuerdo con siete bancos y un fondo de inversión (Citigroup, Deutsche Bank, Royal Bank of Scotland, JP Morgan, Société Générale y Rp Martin) por un importe total de 1,71 millones de euros; al Barclays y a UBS se les concedió la inmunidad en relación con el pago de las multas, pues hicieron una declaración en el pacto. Otros bancos, como HSBC y Crédit Agricole, no estaban de acuerdo con la liquidación y se enfrentaron a penas más altas. La liquidación es la mayor multa jamás impuesta por las autoridades de la competencia europeas.

\section{Análisis.}

¿Qué podemos concluir de estos ejemplos? Por un lado, incluso en áreas claves del mercado interior y el ELSJ, la activación de la jurisdicción para investigar y sancionar queda exclusivamente en manos de los Estados miembros, también en lo que respecta a la estabilidad e integridad del sistema financiero y el funcionamiento del mercado interior. La única excepción es en materia de libre competencia, donde fueron otorgadas a la CE competencias directas de Derecho administrativo sancionador. Por supuesto, la activación de la jurisdicción para investigar y sancionar violaciones en el mercado interior depende del marco legislativo (jurisdicción prescriptiva), pero, adviértase, eso es en gran medida un interés de la soberanía de los Estados-Nación.

No debemos olvidar que, en la aplicación del Derecho público -y esto es muy diferente al Derecho privado- hay una relación muy fuerte entre la legislación aplicable (normas sustantivas y de Derecho procesal) y la jurisdicción, para investigar y juzgar. Aunque 
la ley material aplicable en los mercados financieros y los productos es muy armonizada por el Derecho de la Unión (Directiva del Parlamento Europeo y el Consejo Europeo, 2003), el régimen de aplicación está lejos de ser unificado. Cuando se trata de aplicar las medidas administrativas en el ámbito de los mercados financieros, las autoridades nacionales tienen que reconocer y cumplir en ciertas materias con las obligaciones de aplicación sustantiva y de procedimiento impuestas por la UE. Esto es, por ejemplo, el caso de la aplicación administrativa relacionada con el abuso de mercado (Directiva del Parlamento Europeo y el Consejo Europeo, 2003). Sin embargo, en el ámbito de las tasas de referencia del Libor y Euribor, no existen obligaciones de aplicación de la UE, y queda en manos de todos los Estados miembros la auto-regulación y la ejecución por parte del sector financiero.

Al mismo tiempo, cuando se trata de la aplicación de la ley penal, no existen obligaciones por parte de la UE. Sin embargo, muchos de los Estados miembros disponen en sus legislaciones de delitos específicos y comunes, regulando cuando se pueden aplicar tanto al abuso de mercado y a la manipulación del mercado. La elección del régimen de aplicación (civil, administrativo, penal) es, pues, una mezcla de las obligaciones europeas de menor importancia y las principales opciones legislativas nacionales. El resultado es que la activación de la jurisdicción para investigar y juzgar, depende, en gran medida, de un combinado de la jurisdicción prescriptiva de cada una de las jurisdicciones individuales de cada Estado miembro. De esta manera, los modelos de aplicación de la ley se han quedado atrás de la globalización financiera y fuera de la realidad de los mercados financieros integrados, dentro y fuera de la UE. Por lo tanto, se puede observar claramente que no sólo existe la necesidad de un aumento de la armonización en torno al acatamiento por parte de la UE de los sistemas nacionales de aplicación de la ley, sino también un modelo de aplicación supranacional que pueda coordinar $y$, eventualmente, tomar decisiones vinculantes e individuales al respecto.

Por consiguiente, las consecuencias jurídicas en el ejercicio de la investigación y fallo por cada jurisdicción de un Estado miembro individual en el ELSJ, están lejos de ser claras. El CEO del antiguo Banco Fortis actuó rápidamente para reclamar que las multas impuestas por Holanda impedirían más sanciones administrativas y penales en otros Estados miembros de la UE, basándose en el 
principio ne bis in idem (Vervaele, 2013, pp. 211-229). Su estrategia no funcionó, pues el antiguo Banco Fortis y algunos CEO fueron multados en Bélgica y todos los directores ejecutivos están en el banquillo penal. Sin embargo, la pregunta jurídica que se plantea es si nuevas multas administrativas y sanciones penales son posibles en Bélgica contra las mismas personas jurídicas, o si están excluidos por la imposición de las multas administrativas holandesas. La dimensión transfronteriza no se limita a la cosa juzgada, sino que se extiende a la protección transnacional de los derechos fundamentales, como el principio de legalidad, las garantías procesales, incluido el derecho a guardar silencio, el privilegio a no auto inculparse, etc. (Gless y Vervaele, 2013, pp. 1-10), también en relación con la combinación del cumplimiento punitivo administrativo y penal.

En todos los sentidos es evidente, en primer lugar, que el sistema de persecución en estos casos no refleja una clara coordinación de la jurisdicción en el ELSJ. ¿Quién dice que, en el caso Fortis, el régimen de aplicación administrativa holandesa fue el mecanismo de aplicación más adecuado?, además, ¿por qué tuvieron estos la posibilidad de imponer las sanciones administrativas en primer lugar $\mathrm{y}$, como consecuencia, restringieron otras sanciones administrativas o penales por parte de otras autoridades de los Estados miembros contra las mismas personas jurídicas?, y, por ello, ¿por qué no se ocuparon las autoridades belgas de los intereses de las personas jurídicas involucradas, que ahora se enfrentan a castigos múltiples por los mismos hechos en diferentes jurisdicciones nacionales, pero que estaban operando en un solo ELSJ?

En segundo lugar, debe decirse que las sanciones a las personas jurídicas parecen ser más bien modestas en relación con la magnitud de las víctimas (cientos de miles), la magnitud de los intereses públicos en juego (la integridad del mercado financiero de la UE) y la gran importancia de los mercados financieros referente a los fines del mercado interior. A pesar de la armonización del derecho sustantivo y la parcial aplicación de la ley de la UE, todavía parece posible que el organismo de aplicación que actúa primero es el principal regulador, con lo cual podría impedir más trámites a través del principio ne bis in idem. Pero así otros procedimientos no estuviesen prohibidos por el principio ne bis in idem, es muy ineficaz dominar la aplicación del interés común europeo en segmentos nacionales y dejar en manos de las autoridades de aplicación nacional la plena libertad de intervención, con el resultado de que 
en algunos países no pasa nada y que en otros los procedimientos concurrentes están acaeciendo durante años. Está claro que, en la actualidad, no se puede hablar de un enfoque integrado de la aplicación administrativa y penal, ni en los Estados miembros ni en el ELSJ.

Por último, desde el escándalo de la falsificación de intereses del Libor/Euribor, también podemos concluir que las políticas y estrategias de aplicación de la ley juegan un papel muy importante en la obtención de los objetivos del ELSJ y del mercado interior. El hecho de que los organismos reguladores y ejecutores de los Estados Unidos hayan sido muy activos, es producto de que en las instituciones financieras europeas, es sin duda destacable la inactividad de una gran cantidad de organismos de aplicación que no cumplen sus funciones. Por ello, del ejemplo de Libor/ Euribor, podemos concluir que entre las autoridades encargadas de la aplicación de la ley en la UE hay poca o ninguna coherencia estratégica en la materia. Es más, en algunos países ninguna jurisdicción de aplicación de la ley fue activada, mientras que en otros hubo una racha de actuación entre varias autoridades administrativas y judiciales. Desde el punto de vista del conjunto del ELSJ, el resultado es un mosaico con piezas de una actividad superior y con piezas de una baja actividad o ninguna en absoluto.

No obstante, desde la perspectiva del análisis de nuestros dos ejemplos, podemos seguir reflexionando sobre la relación entre los objetivos de las políticas, la regulación y la aplicación de la ley en el ámbito de los mercados financieros. Los objetivos del mercado interior incluyen la libre circulación de capitales y la protección de la integridad de los mercados financieros (artículo 26 (2), del TFUE); es más, la aplicación de la ley en el ámbito de los mercados financieros es claramente parte del ELSJ (Título V del TFUE). Ello está, por ejemplo, reflejado de manera explícita en el art. 75 TFUE, pero también en los objetivos de la ELSJ, contenidos en el artículo 67 (1-3), en el cual se afirma que "la Unión se esforzará por garantizar un elevado nivel de seguridad mediante medidas de prevención de la delincuencia“. Los fines del mercado interior y el ELSJ están también coordinados en el artículo 3 del TUE, que establecen los principales objetivos de la Unión. Por ello, está asegurado el enlace entre la regulación y la aplicación en los Tratados. Sin embargo, cabe preguntar: ¿cómo surgió en la UE utilizar estas competencias?, ¿acaso la UE llegó a una estrategia para armonizar la aplicación 
de la ley nacional?, ¿estableció la UE un régimen de aplicación supranacional? Para responder a estos interrogantes, en primer lugar abordamos las cuestiones desde el punto de vista general del mercado interno y, luego, lo aplicamos a los mercados financieros.

\section{¿Hay un modelo de la aplicación de políticas de la UE para los sistemas reguladores en el mercado interior?}

Desde la entrada en vigor del Tratado de Lisboa, la CE y en particular la Dirección General de Justicia, han adoptado una postura proactiva en el tema de una política de ejecución penal y también aquello relacionado con la ejecución administrativa. De esta forma, la Dirección General de Justicia en su página web ${ }^{3}$, detalla tres competencias específicas para el Derecho penal en el TFUE: en primer lugar, la UE puede adoptar directivas que establezcan normas mínimas relativas a la definición de las infracciones y de las sanciones penales, acorde con lo regulado en el artículo 83 (1) del TFUE. Asimismo, el Artículo 83 (1) TFUE contiene una lista de diez áreas criminales especialmente graves y con una dimensión transfronteriza; ella incluye el terrorismo, la trata de seres humanos y la explotación sexual de mujeres y niños, el tráfico ilícito de drogas, el tráfico ilícito de armas, el blanqueo de capitales, la corrupción, la falsificación de medios de pago, la delincuencia informática y la delincuencia organizada.

En segundo lugar, la UE también puede adoptar directivas, con arreglo al artículo 83 (2), que establezcan normas mínimas para la definición de las infracciones y las sanciones penales en el ámbito de que se trate, si son esenciales para garantizar la ejecución eficaz de una política armonizada de la UE. En tercer lugar, la Dirección General de Justicia, se refiere a la obligación de proteger los intereses financieros de la UE, en virtud de los artículos 310 (6), 325, 85 y 86 del TFUE que pueden incluir, si es necesaria, la protección mediante el Derecho penal.

En septiembre de 2011, la CE envió una Comunicación bajo el título Hacia una política de Derecho penal de la UE: garantizar la aplicación efectiva de las políticas de la UE mediante el Derecho penal (CE, 2011), que trata específicamente de la competencia del artículo 83 (2), del TFUE. En su primera parte, la Comisión explica con detalle el alcance de la legislación penal de la UE y subraya que el artículo 83 (2) tiene como objetivo el fortalecimiento de la confianza 
mutua, asegurar un cumplimiento efectivo de la legislación y la coherencia y consistencia en la propia legislación penal europea. El artículo 83 (2) del TFUE no enumera los delitos o ámbitos delictivos específicos. Por esta razón, la CE elabora esa Comunicación como una guía para las decisiones políticas, si desea o no utilizar el Derecho penal como un instrumento de ejecución, y, también, en relación con otras herramientas de ejecución, como la administrativa. La Comisión también se ocupa de las elecciones políticas de la UE que requieren el recurso al Derecho penal. Los criterios son la falta de aplicación efectiva o las diferencias significativas entre los Estados miembros, para prevenir una aplicación incoherente de las normas de la UE. Aun así, la CE tendrá que evaluar -caso por caso- los problemas específicos de aplicación y las opciones para aplicar las medidas administrativas y/o penales. Sin embargo, la Comisión indica aquellos campos prioritarios para la armonización del Derecho penal en virtud del artículo 83 (2), del TFUE. Se mencionan tres áreas seleccionadas:

Primera, el sector financiero, por ejemplo en lo relativo a la manipulación del mercado y al uso de información privilegiada (véase la Comunicación sobre Regímenes sancionadores más rigurosos en el sector de servicios financieros COM (2010) 716 de 8.12.2010); segunda, la lucha contra el fraude que afecte a los intereses financieros de la UE; y tercera, la protección del euro contra la falsificación.

La Comisión menciona, además, un conjunto de áreas (no es una lista exclusiva) en el que la aplicación de ley penal podría desempeñar un papel: la economía ilegal y la delincuencia financiera; el transporte por carretera (Véase. Documento de trabajo de la Comisión SEC(2011) 391 de 28.3.2011, que acompaña al Libro Blanco Hoja de ruta hacia un espacio único europeo de transporte: por una política de transportes competitiva y sostenible, COM (2011) 144, de 28.3.2011); la protección de datos (Véase. Un enfoque global de la protección de los datos personales en la Unión Europea, COM (2010) 609 de 4.11.2010); las normas aduaneras; la protección del medio ambiente; la política pesquera; y las políticas de mercado interno (la falsificación, la corrupción, la contratación pública).

Desde la publicación del documento de política, la Comisión también lo ha puesto en práctica. La primera iniciativa del artículo 83 (2) del TFUE, es ciertamente una de las tres áreas ya seleccionadas en la Comunicación de septiembre de 2011, es decir, el sector 
financiero y las sanciones penales aplicables a las operaciones con información privilegiada y la manipulación del mercado ${ }^{4}$. La CE utilizó criterios de política en la Comunicación de septiembre de 2011 para su evaluación y también al producir una comunicación sobre Regímenes sancionadores más rigurosos en el sector de servicios financieros en 2010 (COM (2010) 716 final), basada en una investigación comparativa de los tres comités de supervisores (Comité de Supervisores Bancarios Europeos -CEBS-, Comité de Supervisores Europeo de Seguros y Pensiones de Jubilación CEIOPS- y el Comité de Reguladores de Valores Europeos -CESR-) sobre la equivalencia de los regímenes sancionadores en el sector financiero en los Estados miembros. La revisión por la $\mathrm{CE}$ en cooperación con los comités de supervisores explica detalladamente las discrepancias y debilidades fundamentales en los regímenes sancionadores nacionales.

En efecto, algunas autoridades competentes no tienen a su disposición los tipos importantes de la potestad sancionadora para ciertas violaciones; los niveles de las sanciones pecuniarias administrativas varían considerablemente entre los Estados miembros y son demasiado bajos en algunos Estados; algunas autoridades competentes no pueden hacer frente a las sanciones administrativas de las personas físicas y jurídicas. Además, las autoridades no tienen en cuenta los mismos criterios en la aplicación de sanciones; existen diferencias en la naturaleza (administrativa o penal) de las sanciones previstas en la legislación nacional; y, el nivel de aplicación de las sanciones varía según los Estados miembros.

En la evaluación de impacto de un nuevo conjunto de medidas reguladoras en materia de operaciones con información privilegiada y la manipulación del mercado (CE, 2011, 1218), se identifica otra serie de problemas: no todos los productos y mercados financieros están cubiertos; los reguladores carecen de facultades para hacer cumplir de manera efectiva las regulaciones de abuso de mercado (acceso a los locales, el acceso a los datos de telecomunicaciones, incautación, el intercambio de datos, etc.); las desigualdades en la potestad sancionadora y en las sanciones impuestas son sustanciales. Además, no existe un efecto disuasorio de los regímenes de aplicación; y la aplicación de ley penal no concurre en todos los Estados miembros.

Los desacuerdos existentes en la aplicación de las normas de abuso de mercado pueden quebrantar el mercado único, dejando un margen de discrecionalidad regulatoria y debilitar la cooperación 
transfronteriza de las autoridades policiales. Por ello, en octubre de 2011 la Comisión presentó dos nuevas iniciativas legislativas en materia de abuso de mercado. Estos han sido parte de un paquetenormativo de reformas del sector financiero más amplios. Las dos iniciativas consisten en una propuesta para un reglamento sobre las operaciones con información privilegiada y la manipulación del mercado (abuso del mercado) y una propuesta de directivas sobre las sanciones penales aplicables a las operaciones con información privilegiada y la manipulación del mercado. El reglamento propuesto, sustituye a la Directiva 2003/6/CE, y se contempla en el marco normativo básico. Ésta contiene todas las definiciones, obligaciones y prohibiciones y, también, regula el régimen de ejecución administrativa aplicable, incluidas las sanciones administrativas de carácter punitivo y no punitivo. La propuesta de Directiva es el resultado de la evaluación de la Comisión sobre la necesidad, proporcionalidad y subsidiariedad de la aplicación de ley penal en el sector financiero. De esta manera, la CE llegó a un resultado positivo en cuanto a los delitos graves referentes al abuso de mercado; por lo tanto, la propuesta de Directiva introducirá la obligación de que los Estados miembros establezcan sanciones penales para las violaciones más graves a la normativa del abuso de mercado.

Que estas propuestas sean capaces de alcanzar sus objetivos de, entre otros, aumentar la integridad del mercado y proteger a los inversores, así como de asegurar un único reglamento europeo y nivel en el campo de juego, aún está por verse. En los siguientes párrafos hacemos un análisis de ambas propuestas, en términos de su capacidad expuesta para establecer puntos de referencia en las diferentes autoridades nacionales, para llevar a cabo sus tareas por la dimensión europea (jurisdicción para prescribir e imponer).

\section{El abuso de mercado - Análisis del marco propuesto}

\section{Observaciones generales.}

El paquete legislativo sobre las normas del abuso de mercado se basa en dos artículos diferentes del Tratado de la Unión Europea. La base jurídica del Reglamento es el artículo 114 del TFUE ${ }^{5}$, mientras que la Directiva se basa en el artículo 83 (2), del TFUE ${ }^{6}$. Esta base doble es sorprendente, pues parece estar en contradicción con la ambición de establecer la igualdad de condiciones para los casos de abuso de mercado. La elección del artículo 83 (2) del TFUE como 
base jurídica de la Directiva implica que Dinamarca no participará en la adopción de esta Directiva y que el Reino Unido e Irlanda tienen la opción de elegir, pero no tienen la obligación de formar parte de la Directiva (el Reino Unido optó por retirarse, mientras que Irlanda optó por aceptarla). En otras palabras, bajo la base jurídica elegida, es posible que las obligaciones de ejecución penal que se consideran necesarias para la aplicación efectiva de una política armonizada de la UE, no serán vinculantes en tres países de la UE, incluyendo su centro principal de servicios financieros. En este sentido, la propuesta es un paso hacia atrás y no hacia delante.

Como norma general, el ámbito de aplicación material de las normas de la UE sobre el abuso de mercado se define por la propuesta del reglamento. Este instrumento contiene una serie de disposiciones detalladas que determinan el ámbito de aplicación material del paquete normativo de la UE. En comparación con la actual Directiva 2003/6 (OJ EU 2003 L 96/16), el alcance de las normas se extiende en función de las actividades cubiertas, los instrumentos financieros y los sistemas de negociación. En el marco regulatorio dispuesto, la Directiva de 2003 se consideró fuera de fecha, debido a la aparición de nuevas plataformas de negociación, OTC de comercio y tecnologías, tales como la negociación de alta frecuencia (HFT). El nuevo paquete normativo también abarca los instrumentos financieros relacionados con identificadores de contratos de productos básicos y productos relacionados con las ventas de derechos de emisión. En cuanto a los centros de negociación, el paquete normativo ya no sólo cubre los instrumentos negociados en mercados regulados sino también en sistemas multilaterales de negociación (MTF) y otros sistemas organizados de negociación (OTF). El reglamento también debe incluir cualquiera otra conducta o acción que pueda tener un efecto sobre un instrumento financiero, con independencia de si se lleva a cabo en un centro de negociación (el art. 2 de la propuesta).

El Reglamento especifica además que, como la negociación de instrumentos financieros es cada vez más automatizada, las estrategias abusivas que se llevan a cabo, entre otras, la negociación algorítmica y de alta frecuencia, constituyen la manipulación del mercado. En vista de los esfuerzos para hacer un seguimiento al desarrollo de los mercados y de los objetivos centrales del Reglamento, esta modernización actual de las normas del abuso de mercado tiene sentido. No obstante, las propuestas originales, en sí mismas, ya han necesitado un ajuste durante el curso del 
proceso legislativo, con el fin de incluir la manipulación con los puntos de referencia (como es el escándalo del Euribor/Libor) en las propuestas.

\section{Aplicación de la ley administrativa.}

\section{Jurisdicción prescriptiva.}

El ámbito más ampliado del Reglamento significa que el alcance de la entidad de prohibiciones es también más extensa que el de la actual Directiva 3002/6/CE. El Reglamento obliga a las personas (jurídicas) a que se abstengan de, en resumen, realizar operaciones con información privilegiada y llevar a cabo la divulgación indebida de información (artículo 9) y la manipulación del mercado (artículo 10), de tal manera que creen mecanismos administrativos con el fin de detectar y prevenir la conducta prohibida. Se requieren ciertos actos para cumplir una serie de requisitos adicionales, que incluye unas obligaciones de divulgación a los emisores de los instrumentos financieros, la creación de listas de personas con acceso a la información privilegiada, notificaciones de las transacciones $\mathrm{u}$ órdenes realizadas por los directivos y unas obligaciones con respecto a las recomendaciones de inversión (Capítulo 3). Una vez que el Reglamento entre en vigor, estas normas no sólo serán vinculantes para los actores en los mercados financieros, sino que los Estados miembros también estarán obligados a cumplir estas normas a través de una serie de medidas punitivas y no punitivas (Capítulo 5), incluyendo, entre otras, la retirada o suspensión de la autorización de una empresa de inversión, prohibiciones temporales o incluso permanentes a los directivos de las empresas de inversión, y considerables sanciones pecuniarias, variando hasta al menos $5.000 .000 €$, para las personas físicas y $15.000 .000 €$, o el 15\% de la facturación total anual de las personas jurídicas, en función del tipo de infracción (artículo 26.).

La cuantía máxima de las sanciones pecuniarias administrativas que debían adecuarse al acuerdo sobre el Reglamento, provocó algunos problemas en ciertos Estados miembros. El Derecho constitucional austriaco, por ejemplo, no permite sanciones pecuniarias administrativas similares a la cantidad prevista en el Reglamento (Documento del Consejo 16512/12 de 10 de diciembre de 2012). Por esta razón, el artículo 26 (1) señala que los Estados miembros podrán decidir si establecen o no dichas normas en las sanciones 
administrativas, siempre y cuando estas infracciones ya estén sujetas a sanciones penales en su legislación nacional. El resultado de ello es, como veremos, que los mecanismos deben establecerse con el fin de garantizar una cooperación eficaz en el área de los derechos administrativo y penal.

\section{Jurisdicción de ejecución.}

El artículo 2 (5) del Reglamento establece que las prohibiciones y requisitos de este último se aplican en las acciones relativas a los instrumentos en los que el Reglamento es aplicable, llevadas a cabo dentro y fuera de la Unión Europea. El Reglamento, por tanto, no se limita al ámbito territorial de las normas sustantivas en un territorio nacional determinado. Sin embargo, eso no significa que las autoridades que son responsables de la aplicación de la ley no estén limitadas por las fronteras o hayan obtenido la competencia transnacional con base en el Reglamento. El artículo 16 establece que cada Estado miembro designará una autoridad administrativa única que asumirá las competencias relativas al Reglamento. Dichas autoridades se asegurarán de que las disposiciones del Reglamento se apliquen en todas las acciones llevadas a cabo en su territorio y también fuera del mismo (art. 16). Los casos transnacionales deben ser tratados en cooperación con otras autoridades competentes de los Estados miembros y con la Autoridad Europea de Valores y Mercado (en adelante AEVM). El Reglamento 1095/2010 crea una Autoridad Europea de Supervisión (Autoridad Europea de Valores y Mercados), DO L 331 de la UE 2010/84.

Con el fin de ser capaz de operar con eficacia y hacer realidad la igualdad de condiciones en toda Europa con respecto a la aplicación de las normas de abuso de mercado, las autoridades competentes nacionales también deben tener un determinado conjunto (mínimo) de potestades, incluyendo, entre otras, el acceso a documentos y otros datos, la facultad de exigir información a las personas, llevar a cabo inspecciones in situ y el poder remitir asuntos para su procesamiento penal. Estas autoridades también deben tener la facultad de: entrar en los locales de las personas físicas y jurídicas con el fin de aprehender documentos y otros datos de cualquier tipo, cuando haya una sospecha razonable de que esos documentos y datos están relacionados con la materia objeto de la inspección o investigación, y pueden ser relevantes para probar un caso de abuso de información privilegiada o manipulación del mercado; además, requerir grabaciones de conversaciones telefónicas, las comunicaciones electrónicas u otros 
registros de tráfico de datos en poder de las empresas de inversión, entidades de crédito $\mathrm{u}$ otras instituciones financieras existentes. Así mismo, demandar los registros de tráfico de datos en poder de un operador de telecomunicaciones, cuando haya sospecha razonable de un incumplimiento y cuando dichos registros puedan ser relevantes para la investigación de operaciones con información privilegiada o manipulación del mercado y solicitar la congelación y/o el secuestro de activos (el art. 17 (2)).

Como los últimos tipos de mecanismos constituyen interferencias graves con el derecho a la privacidad y la propiedad, estas mismas se establecen como medidas de investigación penal en muchos países. Por lo tanto, los Estados miembros podrán optar por atribuir directamente o no estas potestades a las autoridades administrativas competentes, pero estableciendo que estas potestades se ejerzan en cooperación mediante una solicitud a la autoridad judicial correspondiente (el art. 17 (1)). Como tal, este enfoque no es nuevo (ver también el art. 12 de la actual Directiva 2003/6/CE).

Sin embargo, el asunto plantea interrogantes en cuanto a qué medidas de protección deberían aplicarse en su lugar ${ }^{7}$. El reglamento remite a la legislación nacional sobre este punto. Se sugiere en la exposición de motivos que para el ejercicio de dicha competencia, la cual pueden constituir unas interferencias graves en el derecho al respeto de la vida privada y familiar, a la propiedad y a las comunicaciones, los Estados miembros deben contar con garantías suficientes y eficaces contra cualquier abuso, por ejemplo, mediante previa autorización de las autoridades judiciales del Estado miembro del cual se trate. Los Estados miembros deben permitir la posibilidad de que las autoridades competentes puedan ejercer dichos poderes intrusivos bajo una extensión necesaria, para así proceder a una adecuada investigación de los casos graves donde no hay medios semejantes para lograr eficazmente el mismo resultado (Considerando el 31 a).

Además de las facultades para realizar investigaciones y de la potestad sancionadora de las autoridades, el artículo 29 prevé la posibilidad de la presentación de informes de violaciones de abuso de mercado, incluidas las disposiciones relativas a la protección de los datos del denunciante de las irregularidades. Los denunciantes deben recibir una protección adecuada contra las represalias, la discriminación $\mathrm{u}$ otros tipos de trato injusto como mínimo. Los Estados miembros también podrán ofrecer incentivos 
financieros a las personas que ofrezcan información importante sobre los posibles incumplimientos del Reglamento, que se podrán conceder de acuerdo con la legislación nacional, siempre que esas personas no tengan obligaciones legales o contractuales de facilitar tal información, que esta información sea nueva, y que dé lugar a la imposición de una sanción o medida administrativa o de una sanción penal por infracción del presente Reglamento.

La igualdad de condiciones y afinidad en la supervisión que debería alcanzarse necesariamente, envuelven a los casos de la cooperación transnacional. Las autoridades competentes nacionales siguen limitadas por las fronteras de sus naciones, necesitan la ayuda de sus equivalentes en los otros Estados dentro (o fuera) de la UE. La designación de una única autoridad competente administrativa en cada Estado miembro, todas con funciones y competencias equivalentes, ayudaría a prevenir la fragmentación de las estructuras de ejecución y facilitaría la creación de un enfoque de red europea. Las autoridades competentes nacionales también trabajan mediante una estrecha cooperación con la AEVM (Art. 18). Dicha autoridad cumple un papel importante en la supervisión de la estructura administrativa supervisora, y puede en ocasiones también facilitar la coordinación entre las autoridades competentes nacionales, o la solución de conflictos entre ellos (Cfr. art. 27 (2)). Además, el artículo 19 del Reglamento exige a las autoridades correspondientes cooperar entre sí, es decir, con los equivalentes en otros Estados miembros, mediante el intercambio de información con previa solicitud o espontáneamente, ya sea para la realización de actos de investigación y ejecución, para investigaciones conjuntas, etcétera.

Sin embargo, el deber de cooperar no va a ir tan lejos como para obligar a las autoridades competentes a cooperar en los casos en que éstas están realizando también investigaciones o que el procedimiento judicial se inició en su jurisdicción, ya que puede dañar la investigación en su territorio (art. 19 (1 bis)). Significa que, bajo el nuevo Reglamento, las autoridades, en absoluto, están incitadas a cooperar en las situaciones esbozadas en la Sección 2. También está en relación con el artículo 27 (2) del mismo Reglamento, según el cual las autoridades en el ejercicio de sus potestades sancionadoras cooperarán, estrechamente, para garantizar que las competencias de supervisión e investigación y sanciones administrativas produzcan los resultados deseados en el Reglamento. Además, coordinarán sus acciones con el fin de evitar posibles duplicaciones y superposiciones 
en la aplicación de su capacidad de supervisión e investigación y sanciones administrativas y multas, para traspasar los casos fronterizos de consentimiento con el artículo 19.

\section{Aplicación de la ley penal.}

Como se ha dicho, la Comisión también presentó una propuesta de Directiva relativa a la aplicación obligatoria de la ley penal en los casos más graves de vulneraciones de las normas de abuso de mercado. Según la Comisión, la adopción de sanciones administrativas por parte de los Estados miembros ha demostrado ser insuficiente para garantizar el cumplimiento de las normas sobre la prevención y la lucha contra el abuso de mercado (Preámbulo de la Directiva propuesta, consideración $5^{\circ}$ ). Diferentes enfoques nacionales quebrantan la igualdad de condiciones en las operaciones del mercado interior y esto puede constituir un incentivo para que las personas cometan abuso de mercado en aquellos Estados miembros que no prevean sanciones penales para esos delitos. Según la Comisión, la introducción de sanciones penales por parte de todos los Estados miembros para aquellos delitos más graves, es esencial para garantizar la aplicación efectiva de la política de la Unión Europea en la lucha contra el abuso de mercado (Preámbulo de la Directiva propuesta, consideración $7^{\circ}$ y $8^{\circ}$ ). La Directiva propuesta introducirá unas normas mínimas para la aplicación de las sanciones penales en las operaciones con información privilegiada, la divulgación ilegal de información privilegiada y manipulación del mercado. También obligará a los Estados miembros a tipificar como delito la incitación, contribución, instigación y el intento de la conducta prohibida. En línea con el principio de ultima ratio, en cuya virtud el Derecho penal debe ser un último recurso, sólo las disposiciones fundamentales más graves de la normativa del abuso de mercado deben ser criminalizadas. No obstante, los Estados miembros son libres de utilizar la vía penal para otras violaciones (una armonización mínima) (Preámbulo de la Directiva propuesta, consideración $15^{\circ}$ ).

La Directiva está estrechamente relacionada con el Reglamento (Ver art. 2). Los cumplimientos de las obligaciones que se derivan de la misma, no significan que los Estados miembros estén ahora obligados a aplicar sólo por la vía penal todas las vulneraciones graves del abuso de mercado. La Directiva no creará obligaciones respecto a la aplicación de dichas sanciones o cualquier otro sistema disponible para hacer cumplir la ley en los casos individuales. Además, 
los Estados miembros no están exentos de la obligación de prever sanciones administrativas y medidas para las infracciones establecidas en el Reglamento, a menos que hayan decidido consignar únicamente sanciones penales para cualquiera de las infracciones en su legislación nacional (Propuesta de la Directiva, las consideraciones 11a y 15a). Por tanto, el conjunto de medidas introduce un régimen dual (a menos que un Estado opte por el Derecho penal por sí solo), lo que deja la opción a las autoridades involucradas de elegir entre la aplicación de la ley administrativa o penal. El principio de ne bis in idem, que figura en el artículo 50 CFR, debe impedir que el sospechoso esté bajo un doble enjuiciamiento o sanción (Propuesta de la Directiva, la consideración 15b).

Debido a que el proyecto de Reglamento y la Directiva propuesta son un conjunto de medidas reguladoras, la propuesta de Directiva se refiere a las definiciones de instrumentos financieros y de información privilegiada en el Reglamento propuesto (Cfr. el Preámbulo, consideración 15b: El ámbito de la presente Directiva se define de una manera tal que se complemente y garantice la aplicación efectiva de las disposiciones establecidas en el Reglamento [MAR]). Sin embargo, curiosamente, se reformulan las definiciones de operaciones con información privilegiada y la manipulación del mercado (Art. 4.3). Esto significa que tan sólo puede esperarse el aumento de interpretaciones divergentes de las autoridades nacionales. En relación con las ambiciones demostradas por alinear los sistemas jurídicos nacionales a otro diseño, se puede decir que esta perspectiva es sorprendente. Además, la Directiva obliga a los Estados miembros a tipificar como delito sólo los casos graves y cuando se cometan intencionalmente (descripciones provisionales de lo que podría constituir una infracción grave se encuentran en el Preámbulo, consideraciones 10 bis y 10 ter). Se introduce, así, un elemento moral (dolo) en la definición de las operaciones con información privilegiada y la manipulación del mercado, que es lo referente a los poseedores primarios, podría decirse que en contradicción con la jurisprudencia del Tribunal de Justicia de la UE y la práctica actual de los Estados miembros que ya aplican las reglas de abuso de mercado mediante el Derecho penal ${ }^{8}$. Los problemas probatorios que surgirán como resultado de esto no se abordan en la Directiva y tan sólo de forma limitada por el Reglamento?.

Por último, con respecto a las sanciones que deben establecerse, la propuesta original de la Directiva señalaba que las sanciones 
penales serían eficaces, proporcionadas y disuasorias, en lo que respecta a las personas físicas. En relación con las personas jurídicas, las sanciones deben ser eficaces, proporcionadas y disuasorias también, a pesar de que no tienen por qué ser necesariamente de carácter penal. Precisamente, la Comisión optó por un perfil bajo con respecto a la armonización de las sanciones. Este sencillo enfoque no sólo es sorprendente en función de la Comunicación de la Comisión de 2001 sobre la Política Criminal (COM, (2011) 573 final), sino también a la vista de la reconsideración por la Comisión en cooperación con los comités de supervisores del cumplimiento de los mercados financieros, la que explica detalladamente las discrepancias sustanciales y debilidades en los regímenes nacionales de sanciones penales (COM, (2010) 716 final). En comparación, la Comisión propuso una Directiva sobre la protección del euro y otras monedas frente a la falsificación, por medio de las leyes penales que originalmente preveía para la armonización del tipo y el nivel de las sanciones penales, incluida la imposición de una privación de la libertad mínima de 6 meses para infracciones graves (COM, (2013) 42 final. Esta disposición ha sido eliminada en las versiones posteriores de la propuesta, véase el documento 14671/13 del Consejo de Bruselas de 11 de octubre 2013). Los razonamientos de la Comisión en la exposición de motivos de esta propuesta, eran que el nivel existente de las sanciones se tornaba en uno de los motivos para una disuasión insuficiente y una protección desigual en toda la Unión Europea de su moneda. Las sanciones mínimas contribuyen, en opinión de la Comisión, a la disuasión y a un sistema a escala comunitaria consistente para la protección del euro. La Comisión también indicó otras ventajas en el punto 18 de la Exposición de Motivos de la propuesta de la falsificación:

La pena mínima de seis meses, ayuda a garantizar la misma prioridad por parte de las fuerzas del orden y las autoridades judiciales hacia los delitos de falsificación del euro y otras monedas $\mathrm{y}$, a su vez, facilita la cooperación transfronteriza. Asimismo, contribuye a aminorar el riesgo de forum-shoping. Además, permite que los autores condenados puedan ser entregados a otros Estados con la ayuda de una orden de detención europea, por lo que la pena o la medida para la custodia puede ser ejecutada.

Fue el Parlamento Europeo quien impulsó medidas de mayor alcance en el dossier del abuso de mercado. En efecto, el 19 de octubre de 2013, el Comité del Parlamento Europeo sobre Asuntos 
Económicos y Monetarios (ponente Arlene McCarthy) modificó la propuesta de Directiva sobre abuso de mercado e introdujo las sanciones privativas de libertad con penas máximas de prisión de al menos cinco y dos años, respectivamente, para las personas físicas, en función del tipo del delito (Parlamento Europeo, 2011, 0297). No obstante, el texto no introdujo condiciones mínimas de prisión, y también se mantuvo en silencio con respecto a las sanciones financieras y a las demás sanciones penales que podrían o pueden imponerse a las personas físicas. Cuando se trata de personas jurídicas, el tenor literal se limita a la responsabilidad que es punible mediante sanciones efectivas, proporcionadas y disuasorias.

Ya el día siete de diciembre de 2013, el Consejo JAI alcanzó un enfoque general sobre el texto (Archivo 17895), a cuyo efecto se mantuvieron las enmiendas de la Comisión del Parlamento Europeo sobre Asuntos Económicos y Monetarios relacionados con los niveles mínimos obligatorios para la pena máxima de prisión. Ahora, las consideraciones se refieren explícitamente a los casos graves de la manipulación del índice de referencia (Euribor y Libor) y a la necesidad de sistemas de sanciones penales comunes en toda la Unión Europea. Todo ello, pese a que esta propuesta deja todavía el régimen de responsabilidad de las personas jurídicas abierto a la responsabilidad penal o no penal, aunque se establece que las sanciones financieras deben establecerse y, además, contiene una lista opcional de las sanciones que puedan imponerse en ambos regímenes. Es más, el proyectado articulado tampoco sujeta ninguna obligación relativa al nivel mínimo de sanciones penales; $y$, aunque tanto la Comisión (en sus planes de política) como el Parlamento Europeo hicieron un alegato a favor de regímenes comunes de sanciones penales en este ámbito, es gracias al PE que el tipo y el nivel de las sanciones penales se ha armonizado hasta cierto punto en la presente Directiva.

\section{Las disimetrías en las estructuras de aplicación.}

Es difícil evaluar los efectos de un sistema que aún no está en su lugar. Sin embargo, ya dimos cuenta de que el paquete normativo propuesto no parece hacer frente a todas las necesidades planteadas por la propia Comisión. Una igualdad de condiciones entre los agentes de la ley europea, por ejemplo, no es aprovechada con las opuestas definiciones de las infracciones en las distintas naciones. No se promovió la cooperación policial entre naciones, siempre las 
autoridades nacionales competentes están en la posición de proteger unilateralmente sus propias investigaciones, por no cooperar con otras autoridades. Las diferencias en los niveles de sanción se mantendrán también después de la introducción de sanciones penales obligatorias. Y la creación de elementos morales para la definición de delito, puede quizás servir al principio de última ratio, pero también implica el recurso - por ejemplo- a ciertas autoridades de investigación con el fin de eludir los problemas probatorios previsibles.

En nuestra opinión, los planes de la Comisión con respecto a la relación entre el Reglamento y la ejecución en el sector financiero, así como las ambiciones de la UE con respecto a la ley penal, aún no toman plenamente en cuenta lo que debería ser el principal centro de coordinación de las políticas de la UE en este ámbito. Ese punto focal es cómo el conjunto de contribuciones ayuda a la elaboración de los objetivos del mercado interior y del ELSJ. Ambos objetivos, que están relacionados entre sí, promueven fuertemente la libre circulación de particulares y empresas, económicamente activas o no, matizando al mismo tiempo un marco para la protección del bien común, incluyendo el crecimiento económico y la creación de empleo, y también la prevención y detección del delito. En el resto de este artículo, vamos a argumentar que es difícil lograr estos objetivos, a no ser que se diera atención a tres puntos de interés los cuales se discuten con más detalle en las siguientes (sub) secciones.

\section{La cooperación transnacional y la coordinación efectiva.}

La UE es un ordenamiento jurídico integrado, donde la cooperación leal entre las autoridades del orden público, ya sea entre diferentes jurisdicciones nacionales, o entre ellas y las de la UE, es vital. La Unión Europea, desde hace mucho tiempo, es activa en la facilitación de estas estructuras. Hemos visto ejemplos de ello anteriormente, con respecto a la cooperación transnacional entre las autoridades administrativas competentes en los casos de abuso de mercado. Estas estructuras también existen en el ámbito del Derecho penal a propósito de, por ejemplo, la entrega de personas para su enjuiciamiento o la ejecución de sanciones (Decisión marco 2002/584/JAI de 13 de junio de 2002 sobre la orden de detención europea y los procedimientos de entrega entre Estados miembros, DO L 190/1 de la UE), o la recogida y traslado de pruebas (Decisión Marco 2008/978 / JAI de 18 de diciembre de 2008 sobre el exhorto europeo con el fin de recabar objetos, documentos y datos 
destinados a procedimientos en materia penal, DO L 350/72 de la UE. El exhorto será reemplazado en su momento por el denominado exhorto europeo de investigación, que ha sido aprobado en diciembre de 2013, por la EP/Comisión LIBE). Esas disposiciones no se limitan a los abusos de mercado, sino que afectan de toda la gama de la ley penal.

La existencia de una gran cantidad de acuerdos internacionales y europeos para la cooperación no significa que una cooperación fluida siempre sea posible, especialmente no en la interfaz de la legislación penal y administrativa. El sistema actual gira en torno a la estructura de la organización de dichas autoridades, en lugar de aquellas tareas que cumplen (Luchtman, 2008, pp. 128-137; Vervaele \& Clip, 2002). Los fiscales y los órganos de investigación (también los competentes para conocer los casos de abuso de mercado) pueden cooperar a través de acuerdos de asistencia judicial recíproca en materia penal (en adelante MLA) o instrumentos de reconocimiento mutuo (en adelante MR); organismos de supervisión financiera (que poseen la facultad de imponer sanciones punitivas o para remitir asuntos a los órganos jurisdiccionales nacionales), tienen sus propios acuerdos (asistencia administrativa bilateral, en adelante MAA), como hemos visto anteriormente. Al mismo tiempo, nos dimos cuenta de que el paquete normativo propuesto sobre el abuso de mercado, introduce un régimen de doble vía, o, en determinadas circunstancias y bajo ciertas condiciones, un régimen de Derecho penal solo.

Así puede ocurrir que las investigaciones de un Estado miembro A se llevan a cabo por los reguladores financieros, mientras que en el Estado B los mismos hechos o relacionados con ellos llamen la atención de la policía y del ministerio público. En ese tipo de situaciones las autoridades involucradas tendrán dificultades para cooperar, ahora que mutuamente no se reconocen como autoridades competentes en el marco del respectivo MLA/MR y en el régimen de MAA. Sobre todo en aquellos casos de abuso de mercado que implican múltiples Estados miembros y las diferentes autoridades nacionales, por tanto, no estarán en la posición de cooperar entre sí directamente. Las autoridades judiciales que buscan información o asistencia de un supervisor financiero en otros lugares de la Unión Europea, entonces, tendrán que acercarse a su supervisor financiero nacional y solicitarle que pida al supervisor de otro Estado miembro su cooperación, o requerir su homólogo judicial en el otro Estado para acercarse a su supervisor nacional; $\mathrm{y}$, luego transferir los datos 
adquiridos de nuevo a él. Esto no sólo requiere mucho tiempo; también es problemático en términos de responsabilidad y la elusión de las garantías legales, sobre todo en los casos en que la asistencia requerida implica interferencias con los derechos fundamentales de las personas afectadas.

El conjunto de medidas reguladoras del Reglamento y la Directiva no se pronuncia sobre esta cuestión. No existen disposiciones que aborden específicamente estos problemas, con la excepción de la situación en la que un Estado miembro concreto ha optado por la aplicación del Derecho penal solamente. En esa situación, el Estado miembro tiene que adoptar las medidas apropiadas que estén en su lugar, para que las autoridades competentes dispongan de todos los poderes necesarios para mantener contacto con las autoridades judiciales dentro de su jurisdicción y, así, poder recibir información específica relacionada con las investigaciones y procesos criminales, partiendo de posibles vulneraciones de este Reglamento y proporcionando al mismo tiempo información a las demás autoridades competentes y a la AEVM, para cumplir con su obligación de cooperar entre sí y con la AEVM a efectos del presente Reglamento (art. 19 (1)). Por supuesto, no está claro por qué esta disposición carece de sistemas que utilizan un régimen de doble vía.

Tampoco está claro cómo este sistema, que se refiere a la cooperación transnacional entre las autoridades penales y las autoridades administrativas, como dos vías separadas, se relaciona con el principio de ne bis in idem. Este principio, recuérdese, establece todas las barreras para un segundo enjuiciamiento por el mismo delito, a condición de que el primer y el segundo procedimiento sean de naturaleza punitiva, y que se refieran al mismo (presunto) delincuente; y ello, téngase en cuenta, aun cuando el artículo 50 de la Carta de los Derechos Fundamentales (CFR) respeta a la Unión Europea en su conjunto, y aunque el principio también cubre combinaciones de Derecho penal y sanciones de Derecho administrativo en el contexto nacional (Véase. TEDH, 10 feb 2009 Zolotukhin vs. Rusia; TJCE 28 de febrero 2013, asunto C-617/10, Åklagaren vs. Hans Åkerberg Fransson.; y Vervaele, 2013b, pp. 113-134), aún no está claro si el principio abarca también combinaciones de Derecho penal y sanciones de Derecho administrativo en un contexto transnacional (Luchtman, 2011; Vervaele, 2013, pp. 211-229).

El Preámbulo de la Directiva propuesta parece confirmar esta última interpretación, cuando señala que los Estados miembros de 
la UE deben garantizar la imposición de sanciones penales sobre la base de los delitos previstos por la Directiva y de las sanciones administrativas de conformidad con el Reglamento, que no debe dar lugar a una violación del principio de ne bis in idem ${ }^{10}$. Esta intelección del asunto también tiene sentido en vista de los objetivos antes mencionados de la Unión Europea y teniendo en cuenta el principio de cooperación leal. Después de todo, una falta de cooperación entre las autoridades administrativas y penales no debe realizarse a expensas de esos actores que están haciendo precisamente lo que la UE trata de estimular, es decir, el uso de sus derechos de libre movimiento para promover una mayor integración europea (e induciendo de este modo las competencias de las distintas autoridades nacionales).

Así las cosas, las posibles consecuencias organizativas de una interpretación tan transnacional del principio, no deben pasarse por alto. Verdaderamente, el principio ne bis in idem requiere una estructura para evitar la distribución de los asuntos de una forma injusta first come, first served (primero en llegar, primero en servirse), y el forum shopping por los demandados o las autoridades. Se fortalecerá así la relación entre los derechos penal y administrativo y requerirá, por lo menos, la posibilidad de una coordinación efectiva de los esfuerzos llevados a cabo por todas las autoridades encargadas de las tareas en el ámbito del Reglamento de abuso de mercado, independientemente de su estructura institucional. Actualmente, se carece de estas normas, como ya lo hemos advertido. Por su propia definición, esta parece ser una tarea del legislador europeo ${ }^{11}$.

\section{Supervisión integral.}

La aplicación de la ley en un orden jurídico integrado no sólo implica un sistema de cooperación rápida y eficaz entre todos los organismos nacionales que participan, sino también la existencia de un mecanismo $u$ órgano que vigila el sistema en su conjunto, en particular, con respecto a los asuntos operacionales. No es difícil imaginar que las diferentes autoridades nacionales competentes pueden tener otros intereses en el desempeño de sus funciones, según demuestra el caso Fortis. Esto, por ejemplo, lleva a situaciones en las que las solicitudes de cooperación no se ejecutan debido a que la autoridad requerida también está llevando a cabo una investigación, o cuando no hay una autoridad nacional competente dispuesta a acceder a una investigación. También, podemos pensar en situaciones en las que las investigaciones se reducen a actores o hechos 
específicos, que afectan directamente a los intereses nacionales. En todas estas situaciones, la pregunta es ¿quién vigila los objetivos del conjunto de medidas reguladoras en su total y cómo el paquete normativo actual se ocupa de los conflictos positivos y negativos de competencia entre las autoridades nacionales competentes?

Debe tenerse en cuenta que las mejoras sustanciales se han hecho, en este sentido, con la entrada de la ESMA (European Securities and Markets Authority). Esta agencia no sólo tiene jurisdicción en lo relativo a las facultades de coordinación entre las autoridades nacionales de supervisión, sino que también puede imponer decisiones individuales vinculantes en situaciones que puedan comprometer gravemente el correcto funcionamiento y la integridad de los sistemas financieros de la UE (Ídem, artículos 18-21 del Reglamento propuesto). El Reglamento de abuso de mercado, también, encomienda a la AEVM la tarea de recoger información sobre todas las medidas administrativas, sanciones y multas impuestas, y otros datos pertinentes (art. 30 (1)). Cuando los Estados miembros han optado por imponer sanciones solamente mediante el Derecho penal, entonces éstos también tienen ciertas obligaciones de información (art. 30 (1a)). Además, a la AEVM se le dará una función para la solución de los conflictos que puedan surgir entre las autoridades administrativas competentes. ESMA dispone de facultades de coordinación con arreglo a la normativa en casos de conflictos reales o potenciales de intereses entre los supervisores nacionales (cf. art. 19 (5) y (6)). Cuando las autoridades competentes, en cuestión, no consiguen llegar a un acuerdo, puede incluso tomar una decisión en el sentido de que deben establecerse medidas específicas, ya sea abstenerse de toda actuación, con el fin de resolver el asunto para garantizar el cumplimiento de la legislación comunitaria.

Sin embargo, la división de la Ley administrativa-penal es preocupante una vez más. El problema es, en primer lugar, que las facultades de ESMA de intervención directa se aplican sólo a las autoridades competentes, como se define en el Reglamento. Dichas autoridades son los supervisores financieros, mencionados en el artículo 16 (autoridades competentes), que se establecerá en virtud del Derecho administrativo (supra sección IV.2.2); ESMA, téngase en cuenta, no tiene competencias con respecto a las autoridades judiciales o policiales. La segunda preocupación, está relacionada con que no existe el equivalente desde la perspectiva de la ley penal de un organismo que realice tareas similares como ESMA, y mucho 
menos que haya una consulta o coordinación entre esa contraparte y ESMA. Eurojust podría desempeñar un papel en la coordinación de las investigaciones nacionales y en la combinación de la elección más apropiada de jurisdicción en materia judicial, pero los casos de abuso de mercado no pertenecen a la competencia de Eurojust todavía. A pesar de que están incluidos en la propuesta de reforma reciente de Eurojust [COM (2013) 535, que contiene una propuesta de Reglamento relativo a la Agencia Europea para la Cooperación en Justicia Penal (Eurojust). Información privilegiada y manipulación del mercado financiero se incluyen en las listas del Anexo 1 que ocupan las competencias materiales definidas en el artículo 3 de la propuesta], las agencias de la UE no estarán en condiciones de emitir decisiones vinculantes para las autoridades nacionales en los casos de conflicto de jurisdicción. Eurojust radica en una fuerte presión de grupo, que se puede ejercer sobre los órganos judiciales nacionales (Groenleer, 2009, pp. 319-320; Herrnfeld, 2012, pp. 147, 149, 155156; Mitsilegas, 2009, pp. 153-154; ), pero, en última instancia, las autoridades judiciales nacionales tomarán una decisión sobre si van a iniciar las investigaciones penales o no.

La situación general que se desprende es, una vez más, que las decisiones nacionales en el Derecho administrativo y / o penal tienen un impacto directo en el funcionamiento del sistema en su totalidad, y las disposiciones para la aplicación de la vía del Derecho penal tras lo que establece la ley administrativa en el área de abuso de mercado. En caso de surgir conflictos, ni ESMA, ni Eurojust son competentes para resolver los conflictos de jurisdicción en la interfaz de la legislación penal y administrativa. El resultado no es tan solo que todavía no haya un mecanismo para evitar un crecimiento de la carga en la persecución y sanción para la persona en cuestión, sino también una pérdida potencial y el uso ineficiente de los recursos.

\section{La protección de los derechos fundamentales.}

El conjunto de medidas reguladoras, en particular el Reglamento, recoge las capacidades que deben estar disponibles para las autoridades administrativas competentes, posiblemente en cooperación con otros organismos nacionales, como las autoridades judiciales. Ya nos dimos cuenta de que algunas de estas potestades son muy intrusivas en función de su capacidad de interferir con los derechos y las libertades de los ciudadanos y en las personas jurídicas, sospechosas o no. Sin embargo, la regulación en sí es casi silenciosa sobre las garantías 
que deberían aplicarse para evitar la interferencia arbitraria o ilegal en la posición de las personas (naturales o jurídicas). Estas garantías se dejan a cargo de la legislación nacional, pues el artículo 17 del Reglamento establece qué competencias están disponibles y también si ellas guardan conformidad con la legislación nacional. La única garantía que uno puede encontrar en la propia norma es que, en determinadas funciones de la investigación, debe existir una sospecha razonable de que los resultados que se obtendrán en el ejercicio de estas facultades pueden ser relevantes para probar el caso o para la investigación. Independientemente de si es necesaria una autorización de una autoridad judicial, ello corresponde a la normativa nacional.

La exposición de motivos también establece que mientras la regulación:

(...) especifica un conjunto mínimo de competencias que las autoridades competentes deben tener, estas facultades han de ejercerse dentro de un justo sistema de la legislación nacional que garantice el respeto de los derechos fundamentales, incluido el derecho a la privacidad. Para el ejercicio de estas facultades, que pueden constituir interferencias graves en el derecho al respeto de la vida privada y familiar, el hogar y las comunicaciones, los Estados miembros deben tener unas garantías adecuadas y eficaces contra cualquier abuso, por ejemplo, la previa autorización correspondiente a la autoridades judiciales de un Estado miembro en cuestión. Los Estados miembros deben permitir la posibilidad de que las autoridades competentes puedan ejercer tales poderes intrusivos en la medida necesaria, para la adecuada investigación de los casos graves donde no hay medios semejantes para lograr efectivamente el mismo resultado (Consideración $31^{a}$ ).

Una vez más, el enfoque del legislador europeo se centra principalmente en la aplicación de estas normas en el contexto nacional. Si existen o no garantías adecuadas y lo que estas garantías constituyen (aprobación judicial, limitación de los fines, la existencia de indicios razonables, etc.) se deja a la legislación nacional. Cada uno de esos sistemas en sí mismo, puede ser totalmente compatible con los requisitos de la Convención Europea de Derechos Humanos o la Carta de la UE sobre los derechos fundamentales. No obstante, esto no quiere decir que estas garantías también funcionen correctamente en los casos de cooperación transnacional. Por ejemplo, la autoridad de un Estado miembro de la UE puede necesitar una autorización judicial previa para obtener ciertos datos de tráfico en su propio ordenamiento jurídico, mientras que otra autoridad podrá no necesitar esto, porque hay otras medidas de seguridad establecidas, 
verbi gratia, la limitación estricta de la finalidad de los datos obtenidos. En los casos en que esta última autoridad pida recopilar y proporcionar los datos de tráfico, ¿cuál será el papel de la autoridad judicial que autoriza en el Estado requerido?, ¿ tendrá esta autoridad que realizar un examen a fondo de la proporcionalidad y subsidiariedad de la solicitud extranjera, como ocurre en los casos nacionales, o va a asumir, de conformidad con el principio de confianza mutua entre los Estados, que dicha prueba ya ha sido realizado en el Estado solicitante, aunque no por un órgano judicial ${ }^{212}$, ¿es incluso capaz de realizar un estudio en profundidad de la prueba, teniendo en cuenta la escasa información que tiene sobre el caso en sí, y que se llevó a cabo en el extranjero? Y si la autoridad otorga la autorización y los datos se recogen y se transfiere, ¿qué pasa con la situación en la que esos datos no podían haber sido inicialmente obtenidos en el Estado solicitante, debido a sus restricciones de limitación del objetivo?, ¿puede un requisito de limitación de tal objetivo dejar de lado las normas aplicables en el reglamento, donde dicha información debe estar disponible para la cooperación transnacional también? En casos como estos, consecuentemente, existe un riesgo real de que la autoridad requerida, en el supuesto de que el Estado requirente respeta los derechos fundamentales, no comprobará si las condiciones y garantías que están vigentes en el Estado solicitante son comparables a sus propias normas. El resultado es que las interferencias con el derecho a la privacidad son comprobadas por el requirente y el Estado requerido (sobreprotección) o nada (infraprotección) (Luchtman, 2008, pp. 162-169).

\section{Conclusiones: desde un estado-nación hacia una perspectiva europea}

El análisis previo sobre los programas propuestos con respecto a la aplicación de las normas de abuso de mercado, revela la existencia de una tendencia en la que el legislador europeo no sólo se centra en un único código normativo europeo que regula normas para los agentes en los mercados financieros, sino también en la convergencia de la supervisión. Esta evolución va de la mano con el incremento de los poderes legislativos europeos en el ámbito de aplicación de la ley en general, incluido el Derecho penal. Con el fin de lograr un adecuado funcionamiento del mercado interior y un ELSJ, el conjunto propuesto de normas de abuso de mercado no sólo define las regulaciones para los agentes de los mercados financieros, sino que también introduce la obligación de hacer cumplir 
estas reglas (punitiva) a través de los derechos administrativo y penal. Para alcanzar esto, es necesario que las estructuras organizativas para la creación de redes y la cooperación, las facultades de investigación y sanciones, se prescriban a nivel europeo.

Aunque se ha progresado con estas propuestas, nuestra opinión es que dichas proposiciones aún no tienen debidamente en cuenta el hecho de que los mercados financieros altamente integrados también necesitan estructuras y poderes sumamente involucrados en la aplicación de la ley, independientemente de la ley orgánica nacional y de la autoridades competentes implicadas (penal o administrativa). En vista de las ambiciosas declaraciones consignadas en los Tratados, en particular las relativas a la creación de un espacio común de justicia para todos los ciudadanos europeos, y el principio de cooperación leal, somos de la opinión de que el legislador europeo debe poner en marcha regulaciones que no sólo faciliten la cooperación efectiva y rápida entre las autoridades nacionales y europeas, independientemente de sus estatutos de Derecho administrativo o penal, sino que también debe asegurarse de que los derechos fundamentales estén protegidos de manera efectiva en los asuntos transnacionales.

Nuestro análisis muestra que todavía hay varios defectos en el sistema propuesto para la aplicación de abuso de mercado. En primer lugar, nos hemos dado cuenta de que las definiciones comunes de las normas sustantivas que definen las reglas del juego y, por lo tanto, el alcance operativo de las autoridades nacionales, siguen mostrando disconformidades. Eso significa que sólo pueden esperarse situaciones en las que las interpretaciones desiguales de las normas obstaculizan el objetivo fundamental de la igualdad de condiciones para los operadores económicos y agentes de la ley.

En segundo lugar, los aspectos propios de Derecho penal en torno al régimen de aplicación europea siguen estando poco desarrollados, tanto en relación con los poderes de investigación disponibles como en torno a las posibilidades de cooperación transnacional y, en particular, a la coordinación y a la supervisión. En tercer lugar, debe decirse que apenas hay disposiciones que se ocupen de la relación entre las medidas administrativas y penales, sobre todo en los casos transnacionales. Eso significa que no existe un organismo responsable en última instancia para el sistema en su conjunto. Por último, no hay atención de ningún tipo para el desarrollo de los derechos fundamentales más allá del contexto del 
Estado-nación con la excepción, quizás, del principio ne bis in idem, que ya cuenta con combinaciones de Derecho penal y administrativo en las sanciones punitivas y se aplica en la UE como un todo.

En caso de presentarse la ocasión y que un tribunal, probablemente el Tribunal de Justicia, declarase que el artículo 50 CFR (ne bis in idem) se aplicara a este tipo de combinaciones, entonces, probablemente esto conducirá a nuevos instrumentos legislativos que tienen por objeto evitar la asignación de asuntos en el base a first come, first served (primero en llegar, primero en servirse). Ya vimos un desarrollo similar en el ámbito del Derecho penal, donde las decisiones históricas de la Corte sobre el Artículo 54-58 CISA (ne bis in idem) (esa jurisprudencia se inició con los asuntos acumulados C-187/01 y C-385/01, Gözütok y Brügge, [2003] ECR I-1345), fueron un importante impulso para una nueva decisión marco 2009/948/ JAI de 30 de noviembre de 2009, sobre prevención y resolución de conflictos de ejercicio de jurisdicción en los procedimientos penales (DO L 328/42 de la UE). Sin embargo, sería desaprovechar una oportunidad limitar el tema de la protección de los derechos fundamentales solo al principio de ne bis in idem. En vísperas de un nuevo programa de política plurianual de justicia penal (el sucesor del programa de Estocolmo), creemos que es hora de que el legislador europeo trate la aplicación de las normas de abuso de mercado como una cuestión que no sólo requiera la integración del sistema por todos los cuerpos de seguridad a nivel nacional, sino también por los órganos legislativos involucrados y no cuando el resultado se determina en gran medida por las barreras organizativas dentro de la Comisión y el Consejo.

Finalmente, el diseño de la ejecución de los intereses que requieren protección en el mercado interno y en el ELSJ, no sólo tienen una dimensión interna de la UE, sino también una dimensión externa de la UE. A partir del ejemplo Libor/Euribor parece haber un modelo de externalización de la ejecución de un único asunto de mercado en las autoridades estadounidenses. La autoridad de competencia comunitaria entró con sanciones fuertes, pero tarde y sólo relacionadas con la distorsión del mercado. Las autoridades nacionales no desempeñaron ningún papel o la mayoría lo hicieron dentro de su agenda nacional. Esto no parece ser una estrategia común, bien cuando se trata de la dimensión exterior de la ejecución de los mercados financieros. Esto es destacable a la vista de la existencia de un tipo de estrategias en el área del 
campo de la competencia, donde se ha elaborado un convenio $^{13}$ para proporcionar a las reuniones bilaterales periódicas una serie de estrategias, como compartir información sobre las actividades de ejecución en curso y prioridades, discutir los cambios de política, y examinar asuntos de interés mutuo relacionados con la aplicación de las leyes de competencia.

\section{Notas}

1 En general, la Fiscalía holandesa no publica ninguna de las comunicaciones sobre la apertura o no de investigaciones judiciales financieras o la existencia de investigaciones judiciales financieras en curso. Sin embargo, en Bélgica esto se hace en la práctica actual.

2 Este acuerdo forma parte de los esfuerzos en curso del presidente Barack Obama por la Unidad Especial de Control del Fraude Financiero. El presidente Obama estableció la interinstitucional Unidad Especial de Control Financiero para emprender un esfuerzo provocador, coordinado y proactivo para investigar y enjuiciar los delitos financieros. El grupo de trabajo incluye a representantes de una amplia gama de agencias federales, autoridades reguladoras, inspectores generales y las fuerzas del orden estatal y local que, trabajando juntos, aportan una amplia gama de recursos en la ejecución penal y civil. El grupo de trabajo labora para mejorar los esfuerzos de todo el poder ejecutivo federal, y con socios estatales y locales, para investigar y enjuiciar los delitos financieros significativos, asegurar un castigo justo y eficaz para aquellos que cometen delitos financieros, combatir la discriminación en los mercados de préstamos y financieros, y recuperar fondos para las víctimas de delitos financieros.

3 http://ec.europa.eu/justice/criminal/criminal-law-policy/index_en.htm

4 Para las otras propuestas sobre la protección penal de los intereses financieros de la UE y de la moneda única (euro), Véase. Vervaele, 2013a, pp. 43-72.

5 Véase, COM (2011) 651 para la propuesta original, modificada por la COM (2012) 421; para nuestro análisis, hemos utilizado el texto del documento 11384/13 del Consejo, de ocho de julio de 2013, que contiene la versión consolidada del acuerdo político con el Parlamento Europeo sobre el reglamento. El texto aprobado fue publicado como Reglamento (UE) No. 596/2014 del Parlamento Europeo y del Consejo, de 16 de abril de 2014 , sobre el abuso de mercado (Reglamento sobre abuso de mercado) y por el que se derogan la Directiva 2003/6/CE del Parlamento Europeo y del Consejo, y las Directivas 2003/124/CE, 2003/125/ CE y 2004/72/CE de la Comisión Texto pertinente a efectos del EEE, OJ L 173, 12.06.2014 
6 Véase, COM (2011) 654 para la propuesta original, modificada por la COM (2012) 420; para nuestro análisis, hemos utilizado el texto de compromiso final del documento del Consejo 17895/13 de 19 de diciembre 2013. El texto aprobado fue publicado como Directiva 2014/57/UE del Parlamento Europeo y del Consejo, de 16 de abril de 2014, sobre las sanciones penales aplicables al abuso de mercado (Directiva sobre abuso de mercado), OJ L 173, 12.06.2014.

7 Véase, por ejemplo, las similares preocupaciones expresadas en la Declaración de Suecia, Austria, República Checa y Alemania en el documento del Consejo 11384/13 de 27 de junio de 2013: Cualquier expansión en el acceso a los datos de tráfico fuera de los procedimientos judiciales establecería un peligroso precedente para otros expedientes de la UE.

8 En Spector Photo Group, el Tribunal de Justicia de la UE considera que esto se debe a la naturaleza específica de las operaciones con información privilegiada que permite una presunción de que el elemento de intencionalidad, una vez que los elementos constitutivos mencionados en esta disposición están presentes y por la finalidad de la Directiva 2003/6, son para garantizar la integridad de los mercados financieros comunitarios y aumentar la confianza de los inversores en dichos mercados. El legislador comunitario, según el Tribunal de Justicia Europeo, optó por un mecanismo de prevención y de sanciones administrativas para operaciones con información privilegiada, cuya eficacia se debilitaría si los hechos objeto de un análisis sistemático diesen con la existencia de un elemento de intencionalidad; véase la sentencia de 45/08, Spector Photo Group y Van Raemdonck, [2009] ECR I-12073, p.p. 35-38.

9 En particular, a través de las técnicas de investigación que se introducen, y las disposiciones sobre la protección de denuncia de irregularidades; sección 4.2.2. Si la evidencia que se encuentra de este modo, puede ser utilizado como prueba en el proceso penal, estableciendo bajo qué condiciones, queda para la legislación nacional.

10 En el preámbulo, la consideración 15b. La Presidencia del Consejo también escribió que el Grupo de Trabajo sobre el Derecho Penal Sustantivo (DROIPEN) indicó que el principio ne bis in idem podría presentarse si las autoridades competentes de uno (o más) Estados miembros aplican a la misma conducta de una persona tanto las sanciones penales previstas en su legislación nacional para ese delito y las sanciones administrativas previstas por MAR (...). Cabe señalar, en este contexto, que el principio ne bis in idem se aplica a través de las fronteras de la UE.

11 Documento del Consejo 14598/12 de 17 de octubre de 2012, p. 4-5, revela que se deja a las autoridades nacionales evitar una situación en 
la que, de conformidad con las normas de su ordenamiento jurídico, la aplicación simultánea de diferentes tipos de sanciones vulneren el derecho de la persona a no ser juzgado dos veces por el mismo delito en un caso concreto. Esta interpretación sólo es correcto, cuando el principio se limita a los casos nacionales. Ese mismo documento sugiere que sin embargo este no es el caso.

12 Situaciones como éstas han surgido en la legislación sobre competencia, en la que el Tribunal de Justicia ha desarrollado un modelo para una 'división del trabajo' entre los órganos jurisdiccionales nacionales y el Tribunal de Justicia Europeo para el control de las medidas coercitivas; véase la sentencia de 94/00, Roquette Frères, [2002] ECR I-9011. Este modelo carece de otras áreas.

13 Acuerdo entre el Gobierno de los Estados Unidos de América y la Comisión de las Comunidades Europeas en relación con la aplicación de sus normas de competencia - Intercambio de cartas interpretativas con el Gobierno de los Estados Unidos de América. Diario Oficial L 095 de 27/04/1995 P. 0047-0.052

\section{Referencias}

Bovens, M.; Curtin, D.; Hart, P. (eds.) (2010). The real world of EU accountability - What deficit? Oxford: Oxford University Press.

Busuioc, M. (2010). The Accountability of European Agencies - Legal Provisions and Ongoing Practices, Delft: Eburon.

Comisión Europea. (2010). Comunicación de la Comisión al Parlamento Europeo, al Consejo, al Comité Económico y Social Europeo y al Comité de las Regiones. (716). Bruselas.

Comisión Europea. (2010). Comunicación «Un enfoque global de la protección de los datos personales en la Unión Europea», COM (2010) 609 de 4.11.2010, Bruselas.

Comisión Europea (2010). Comunicación sobre «Regímenes sancionadores más rigurosos en el sector de servicios financieros» COM (2010) 716 de 8.12.2010.

Comisión Europea. (2011). Communication from The Commission to The European Parliament, The Council, The European Economic And Social Committee and The Committee of The Regions. Towards an EU Criminal Policy: Ensuring The Effective Implementation of EU Policies through Criminal Law. Bruselas.

Comisión Europea. (2011). Documento de trabajo de la Comisión SEC (2011) 391 de 28.3.2011, que acompaña al Libro Blanco «Hoja de ruta hacia un espacio único europeo de transporte: por una política de transportes competitiva y sostenible», COM 144, de 28.3.2011. 
Comisión Europea. (2011). Commission Staff Working Paper Executive Summary of The Impact Assessment. Bruselas.

Comisión Europea, Dirección General de Justicia. (2013). Política en Derecho Penal. Bruselas.

Comisión Europea. (2013). (Decisión 535). Propuesta de Reglamento relativo a la Agencia Europea para la Cooperación en Justicia Penal (Eurojust). Bruselas.

Consejo de la Unión Europea. (2002). (Decisión 584/JAI). Relativa a la orden de detención europea y a los procedimientos de entrega entre Estados miembros.

Consejo de la Unión Europea (2003). Directiva 2003/6/CE del Parlamento Europeo y del Consejo, de 28 de enero de 2003, sobre las operaciones con información privilegiada y la manipulación del mercado (abuso del mercado).

Consejo de la Unión Europea. (2008). (Decisión 978/JAI). Sobre el exhorto europeo con el fin de recabar objetos, documentos y datos destinados a procedimientos en materia penal.

Consejo de la Unión Europea (2012). Documento del Consejo 16512/12 de 10 de diciembre.

Consejo de la Unión Europea. (2013). Proposal for a Directive of the European Parliament and of the Council on criminal sanctions for insider dealing and market manipulation (17895/13). Bruselas.

DNB en AFM onderzoeken manipulatie Libor-rente. (27 de julio de 2012). RTZL. Recuperado de http://www.rtlnieuws.nl/economie/dnb-enafm-onderzoeken-manipulatie-libor-rente

Euribor rate. (s.f.). Recuperado de http://www.euribor-rates.eu/panelbanks.asp

FSA. (27 de junio de 2012). Barclays fined 59.5 million for significant failings in relation to LIBOR and EURIBOR. (FSA/PN/070/2012). Recuperado de http://www.fsa.gov.uk/library/communication/pr/2012/070.shtml

Gless, S. \& Vervaele, J. (2013). Law Should Govern: Aspiring General Principles for Transnational Criminal Justice. Utrecht Law Review, 9(4) pp. 1-10. Recuperado de http://www.utrechtlawreview.org/index. $\mathrm{php} / \mathrm{ulr}$

Groenleer, M. (2009). The autonomy of European Union Agencies. Delft: Eburon.

Herrnfeld. H. H. (2012). Jurisdiktionskonflikte bei grenzüberschreidender Kriminalität - Ein Rechtsvergleich zum Internationalen Strafrecht, Göttingen. En A. Sinn (ed.). Osnabrück: VER unipress. Universitatsverlag Osnabrück. 
Luchtman, M. (2008). European cooperation between financial supervisory authorities, tax authorities and judicial authorities, 128-137. Antwerpen. Oxford: Intersentia.

Luchtman, M. (2011). Transnational Law Enforcement in the European Union and the ne bis in idem principle, Review of European Administrative Law 4, pp. 5-29.

Mitsilegas, V. (2009). EU criminal law. Oxford. Portland, Oregon: Hart.

Parlamento Europeo y Consejo Europeo. (2003). Directiva (2003/6/CE) Sobre las operaciones con información privilegiada y la manipulación del mercado (Abuso del mercado). Recuperado de http://eur-lex.europa.eu/ LexUriServ/LexUriServ.do?uri=OJ:L:2003:096:0016:0016:EN:PDF

Parlamento Europeo, Comité de asuntos económicos y monetarios/McCarthy, A. (2012). On the proposal for a directive of the European Parliament and of the Council on criminal sanctions for insider dealing and market manipulation.

Parlamento Europeo y Consejo Europeo. (2014). Directiva (2014/57/UE). Sobre las sanciones penales aplicables al abuso de mercado (Directiva sobre abuso de mercado).

Treanor, J. (6 de julio de 2012). Serious Fraud Office to investigate Libor manipulation. The guardian. Recuperado de http://www.theguardian. com/business/2012/jul/06/serious-fraud-office-libor-investigation

Vervaele, J. \& Clip, A. (Eds.). (2002). European Cooperation between Tax, Customs, and Judicial Authorities. Den Haag: Kluwer.

Vervaele, J. (2013). Ne bis in idem: Towards a Transnational Constitutional Principle in the EU? En S. Gless \& J. Vervaele (Eds.), Special on transnational criminal justice, Utrecht Law Review, 9, no. 4, pp. 211-229.

Vervaele, J. (2013a). Harmonised Policies and the harmonization of substantive criminal law. En F. Galli y A. Weyembergh (Eds.), Appro-ximation of substantive criminal law in the EU. (pp. 43-72). Bruselas: Ediciones UBL.

Vervaele, J. (2013b). The Application of the EU Charter of Fundamental Rights and its Ne bis in idem Principle in the Member States of the EU. Review of European Administrative Law, 6, 2013-1. 113-134.

Unión Europea. Directiva 6/2003 / CE de 28 de enero de 2003 sobre operaciones con información privilegiada y la manipulación del mercado (abuso del mercado), OJ EU L 96/16.

Unión Europea (2002). Decisión marco 2002/584 / JAI de 13 de junio de 2002 sobre la orden de detención europea y los procedimientos de entrega entre Estados miembros, DO L 190/1 de la UE. 
U.S. Commodity futures trading commission. (27 de junio de 2012). CFTC Orders Barclays to pay $\$ 200$ Million Penalty for attempted manipulation of and false reporting concerning LIBOR and Euribor Benchmark Interest Rates. Recuperado de http://www.cftc.gov/PressRoom/PressReleases/pr 6289-12

Zolotukhin v Rusia. (2009, febrero 10). Tribunal Europeo de Derechos Humanos-[TEDH]. 
